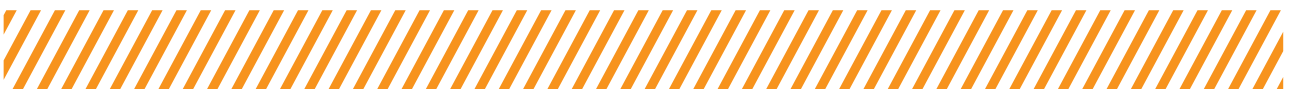

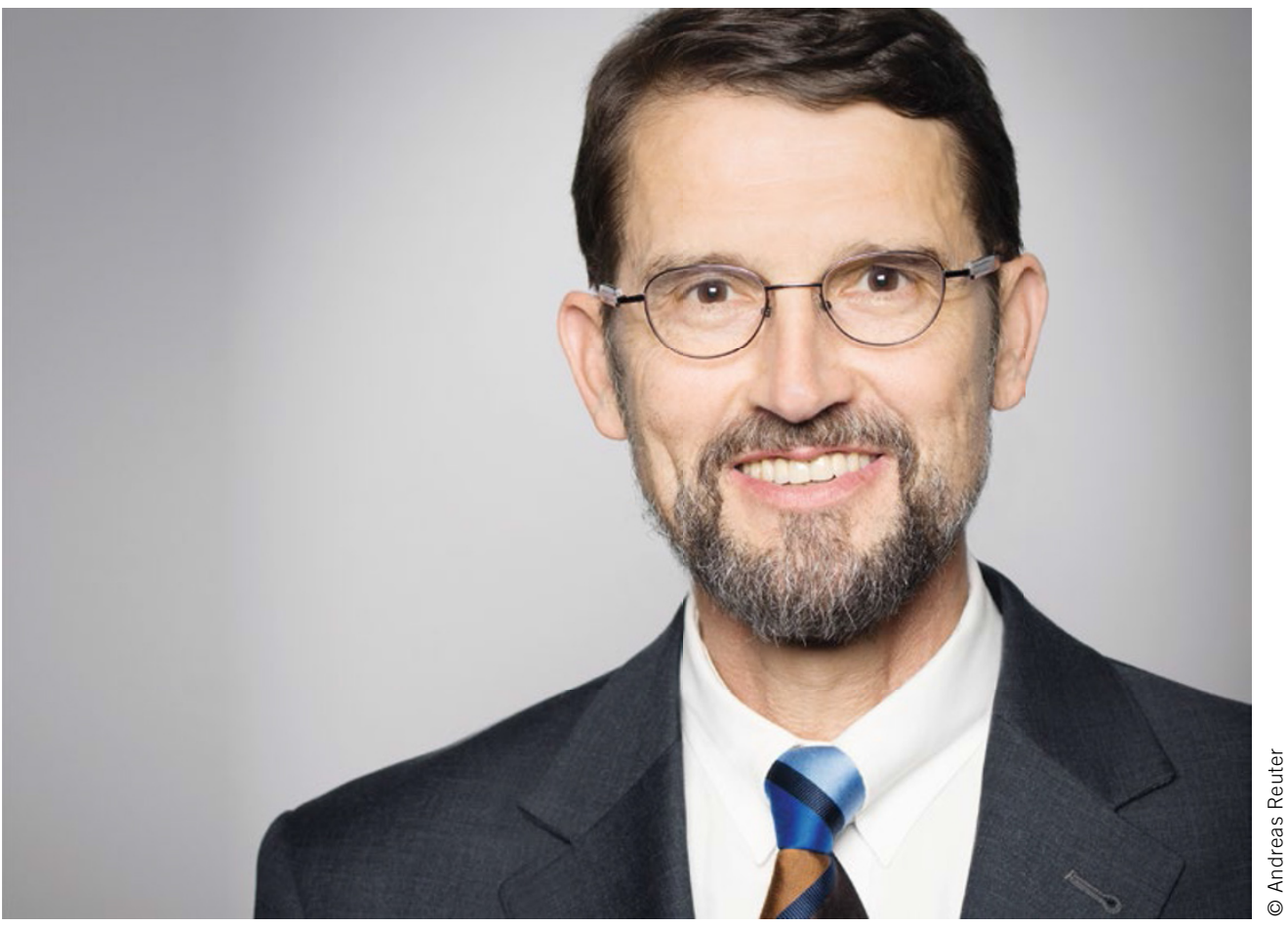

Andreas Reuter

Rechtsanwalt in Stuttgart

\section{Datensicherheit - ein Muss bei funktionaler Sicherheit}

Neue Systeme im Fahrzeug sind zunehmend auf den Austausch von Daten über externe Schnittstellen angewiesen. Damit steigt das Risiko gefährlicher Eingriffe durch Dritte. Datenschutz und Datensicherheit standen bislang in der Automobilindustrie nicht im Fokus, da ein direkter, vom Fahrer nicht kontrollierter Zugriff durch Dritte aufgrund der Abschottung der Fahrzeugsysteme nach außen kaum möglich war. Auch deshalb enthält die ISO 26262 zur Datensicherheit keine Anforderungen. Mit der Entwicklung von Systemen des hoch- oder vollautomatisierten Fahrens ändert sich die Sachlage, da solche Systeme auf den Austausch hochpräziser Daten über externe Schnittstellen in Echtzeit angewiesen sind. Diese können ohne den Fahrer als Filter direkt auf die Längs- und Querführung des Fahrzeugs Einfluss nehmen. Sind die Daten fehlerhaft, besteht unter Umständen unmittelbare Lebensgefahr.

Bislang ungeklärt ist, wie und mit welchem Aufwand dem Risiko versehentlich oder bewusst verfälschter Daten begegnet werden muss. Der Bundesgerichtshof hat wie in einem AirbagUrteil 2009 zwei grundlegende Anforderungen herausgearbeitet. Erstens: Der Autohersteller muss sämtliche Vorkehrungen zur Abwehr von den beim Betrieb zu erwartenden Gefahren und Risiken treffen, die ihm nach dem Stand der Technik konstruktiv möglich und angesichts der Gefährdung auch zuzumuten sind. Zweitens: Produkte, die trotz Einsatz aller technisch verfügbaren und zumutbaren Möglichkeiten nicht die Sicherheit bieten, die vernünftigerweise erwartet werden darf, dürfen nicht in den Verkehr gebracht werden. Systeme, die auf einen Datenaustausch über externe Schnittstellen angewiesen sind, dürfen also erst dann in den Verkehr gebracht werden, wenn eine Beeinträchtigung des sicheren Betriebs durch einen solchen Datenaustausch entweder technisch ausgeschlossen ist oder durch sonstige Vorkehrungen sichergestellt werden kann, dass die Nutzung dieser Systeme im Rahmen der berechtigten Sicherheitserwartung bleibt. Dabei kommt es bei sicherheitsrelevanten Systemen meist auf die Integrität der verwendeten Daten, das heißt auf die Identität des Senders und die Unverfälschtheit des Inhalts an.

Ohne ein überzeugendes Konzept zur Absicherung einer angemessenen Datensicherheit - von der Systemarchitektur, der Generierung und Bereitstellung richtiger und vollständiger Daten, der rechtzeitigen und unveränderten Übermittlung bis hin zur spezifikationsgerechten Nutzung dieser Daten im Fahrzeug - wäre eine Einführung von Systemen zum automatisierten Fahren mit einem unkalkulierbaren Haftungsrisiko verbunden. 